\title{
Potensi Antioksidan Rumput Laut Gracilaria verrucosa Dari Pantai Gunung Kidul, Yogyakarta
}

\author{
Wahyu Febrianto*, Ali Djunaedi, Suryono Suryono, Gunawan Widi Santosa dan \\ Sunaryo Sunaryo
}

\author{
Departemen IImu Kelautan, Fakultas Perikanan dan IImu Kelautan, Universitas Diponegoro \\ JI. Prof. H. Soedharto, SH., Tembalang, Semarang, Indonesia 50275 \\ Email: wahyu.febrianto.rf@gmail.com
}

\begin{abstract}
Antioxidant Potential of Gracilaria verrucosa Seaweed from Gunung Kidul Beach, Yogyakarta

Gracilaria verrucosa is red algae that has been widely used as an antioxidant. This research was conducted to test antioxidant activity, total phenolic content and bioactive compound of Gracilaria verrucosa obtained from Pok Tunggal Beach and Ngandong Beach, Gunung Kidul, Yogyakarta. Research was carried out by descriptive method. Samples were fresh and taken from the beach, then macerated for 3x24 hours in a methanol solvent. Antioxidant test was carried out by electron transfer method with DPPH $0.1 \mathrm{mM}$ and measurement of antioxidant activity using. Total phenolic contents were measured using the Folin-ciocalteau method using gallic acid standard on $725 \mathrm{~nm}$ wavelength. The phytochemical content observated by changing of extract color by reagent. Pigment contents were measured using spectrophotometric methods at wavelengths 636 and 663 (chlorophyll-a and chlorophyll-b) and $480 \mathrm{~nm}$ (carotenoids). The results showed that IC50 value extract of Pok Tunggal Beach and Ngandong Beach were 188,53 ppm and 168,76 ppm. Phenolic content of each extract were 16,527 and 17,497 mg GAE / g sample weight). Chlorophylla levels were 7,132 and $4,357 \mathrm{mg} / \mathrm{g}$, chlorophyll-b were 8,335 and $5,401 \mathrm{mg} / \mathrm{g}$, carotenoids were 31,625 and 35,494 $\mu \mathrm{mol} / \mathrm{g}$. Gracilaria verrucosa from Ngandong Beach have antioxidant activity.
\end{abstract}

Keywords: Gracilaria verrucosa; antioxidant; DPPH; phytochemical

\begin{abstract}
Abstrak
Gracilaria verrucosa merupakan alga merah yang pemanfaatannya sudah banyak dilakukan sebagai antioksidan. Penelitian ini bertujuan untuk mengetahui potensi antioksidan, menghitung kadar fenolat total, dan senyawa bioaktif yang terkandung pada Gracilaria verrucosa yang diperoleh dari Pantai Pok Tunggal dan Pantai Ngandong, Gunung Kidul, Yogyakarta. Penelitian ini dilakukan dengan metode deskriptif. Sampel segar diambil langsung dari pantai, kemudian dimaserasi selama $3 \times 24$ jam dalam pelarut metanol. Uji antioksidan dilakukan dengan metode transfer elektron dengan DPPH 0,1 mM dan pengukuran aktivitas antioksidan menggunakan perhitungan nilai $\mathrm{IC}_{50}$. Kadar fenolat total diukur menggunakan metode Folinciocalteau dengan asam galat sebagai standar pada panjang gelombang $725 \mathrm{~nm}$. Kandungan fitokimia diuji menggunakan pengamatan perubahan warna ekstrak saat diberikan pereaksi. Kadar pigmen diukur menggunakan metode spektrofotometri pada panjang gelombang 636, 663 (klorofil-a dan klorofil-b) dan $480 \mathrm{~nm}$ (karotenoid). Hasil menunjukkan bahwa nilai IC 50 ekstrak sampel dari Pantai Pok Tunggal dan Pantai Ngandong berturut-turut adalah 188,53 ppm dan $168,76 \mathrm{ppm}$. Kadar fenolat masing-masing ekstrak sebesar 16,527 dan 17,497 mg GAE/g berat sampel). Kadar klorofil-a sebesar 7,132 dan 4,357 mg/g, klorofil-b sebesar 8,335 dan 5,401 mg/g, karotenoid sebesar 31,625 dam 35,494 $\mathrm{mmol} / \mathrm{g}$. Gracilaria verrucosa dari Pantai Ngandong dan Pantai Pok Tunggal memiliki potensi antioksidan.
\end{abstract}

Kata kunci: Gracilaria verrucosa; antioksidan; DPPH; fitokimia 


\section{PENDAHULUAN}

Pemanfaatan rumput laut saat ini beragam dan mencakup ke dalam bidang pangan, industri, serta farmasi. Rumput laut diketahui memiliki senyawa bioaktif yang beragam yang masing - masing spesies memiliki keunikannya tersendiri. Rumput laut Gracilaria verrucosa yang termasuk ke dalam golongan rumput laut merah. Menurut penelitian yang dilakukan Arunkumar et al. (2014) kandungan klorofil total dan pigmen aksesoris pada Gracilaria verrucosa lebih besar dibandingkan dengan rumput laut merah lainnya. Pigmen yang terkandung pada rumput laut memiliki potensi untuk dimanfaatkan sebagai antioksidan (Pumas et al., 2012).

Senyawa yang mampu mendonorkan satu elektron kepada senyawa oksidan radikal sehingga dapat menghambat proses oksidasi dapat disebut sebagai senyawa antioksidan. Senyawa radikal bebas cenderung untuk menyerap elektron di sekitarnya karena memiliki elektron tidak berpasangan. Antioksidan dapat diperoleh dari alam dengan proses ekstraksi bahan alam. Antioksidan jenis ini disebut sebagai antioksidan alami dan jumlahnya terbatas (Sayuti dan Yenrina, 2015; Yadav et al., 2016).

Antioksidan alami tidak memiliki efek samping seperti yang terjadi saat menggunakan antioksidan sintetis (Choe dan Min, 2009). Antioksidan sintetis seperti tertbutylhydroquinone (TBHQ), butylated hydroxianisol (BHA), dan butylated hydroxytolvene (BHT) sering ditemukan terkandung dalam produk produk pangan yang beredar di pasaran. Konsumsi antioksidan sintetis secara terus menerus akan menyebabkan kerusakan hati (Fitri, 2013).

Berdasarkan penelitian yang dilakukan oleh Widowati et al. (2014) dan Cyril et al. (2017), Gracilaria verrucosa mengandung metabolit sekunder seperti alkaloid, flavonoid, terpenoid serta senyawa bioaktif lainnya. Alkaloid, flavonoid, dan terpenoid merupakan senyawa bioaktif yang dapat berfungsi sebagai antijamur dan antioksidan (Saxena et al., 2013). Penelitian yang dilakukan oleh de Almeida et al. (2011) menunjukkan kemampuan Gracilaria verrucosa sebagai anti-toksik, anti-inflamasi, antioksidan, dan anti-hipertensi.

Pantai Pok Tunggal, Gunung Kidul dan Pantai Ngandong, Gunung Kidul memiliki karakteristik berupa pantai dengan susunan karang mati di bibir pantainya. Lokasinya yang berada di selatan Pulau Jawa dan menghadap langsung ke Samudera Hindia, menjadikan pantai ini memiliki gelombang yang cukup besar. Menurut Ariani et al. (2017), pada umumnya rumput laut Gracilaria memiliki habitat di pantai yang memiliki substrat karang berpasir dengan kedalaman yang dangkal serta hangat.

Tujuan dari penelitian ini adalah mengetahui potensi antioksidan, kadar klorofil-a, klorofil-b, karotenoid, dan metabolit sekunder pada rumput laut Gracilaria verrucosa dari Pantai Pok Tunggal dan Pantai Ngandong.

\section{MATERI DAN METODE}

Materi dalam penelitian ini adalah rumput laut divisi Rhodophyta spesies Gracilaria verrucosa yang diperoleh dari Pantai Pok Tunggal dan Pantai Ngandong, Gunung Kidul, Yogyakarta. Metode penelitian yang digunakan adalah deskriptif eksploratif. Proses ekstraksi sampel dilakukan berdasarkan metode yang telah dilakukan oleh Rohimat et al. (2014), yang di modifikasi volume pelarutnya. Perhitungan rendemen berdasarkan Sani et al. (2014).

Pengujian senyawa fitokimia, Uji alkaloid dan Uji flavonoid dilakukan dengan mengacu metoda Suzery dan Kusrini (2004). Aktivitas antioksidan dilakukan berdasarkan penelitian Shekhar dan Anju (2014) dan Pramesti et al., (2017).

Pengujian total fenolat dilakukan denan mengacu pada Yangthong et al. (2009), Sharma et al. (2011) dan Santoso et al. (2012) dengan modifikasi jenis sampelnya. Penentuan kadar klorofil total dan karotenoid mengacu pada Lichtenthaler (1987), dan Kurniawan et al. (2010). Hasil pegukuran absorbansi kemudian dihitung menggunakan perhitungan oleh Lichtenthaler (1987). 


\section{HASIL DAN PEMBAHASAN}

Ekstrak sampel dari kedua pantai memiliki hasil akhir berwarna hijau pekat dengan bentuk seperti pasta. Berat ekstrak dan rendemen ekstrak sampel yang berasal dari pantai Ngandong lebih besar dibanding ekstrak sampel yang berasal dari Pantai Pok Tunggal.

Hasil ekstraksi yang menunjukkan bahwa berat ekstrak dan angka rendemen ekstrak yang diperoleh dari pantai Ngandong lebih besar dari yang diperoleh dari pantai Pok Tunggal (Gambar 1). Lebih lanjut, hasil ekstraksi yang lebih besar diduga karena Gracilaria verrucosa memiliki kandungan senyawa aktif yang lebih banyak sehingga mempengaruhi berat rendemen. Pernyataan ini sesuai dengan Sayuti (2017) yang menyatakan bahwa berat rendemen dipengaruhi kandungan senyawa aktif suatu sumber.

Warna kehijauan pekat pada hasil ekstraksi mengindikasikan bahwa sampel memiliki banyak kandungan klorofil. Klorofil dapat keluar dari dinding sel dikarenakan pemecahan dinding sel saat proses maserasi (Hanapi et al., 2013). Aktivitas antioksidan ekstrak dilihat dengan nilai $I_{50}$ (Inhibition Concentration 50\%). Nilai IC 50 dapat di hitung berdasarkan grafik hubungan antara \% inhibisi terhadap konsentrasi ekstrak. Persentase (\%) inhibisi dari kedua ekstrak meningkat seiringan dengan meningkatnya konsentrasi. Pada penelitian ini konsentrasi

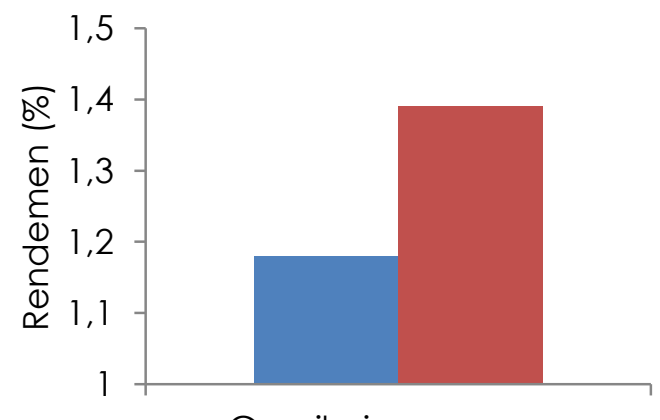

Gracilaria verrucosa

- Pok Tunggal ngandong

Gambar 1. Rendemen ekstraksi Gracilaria verrucosa

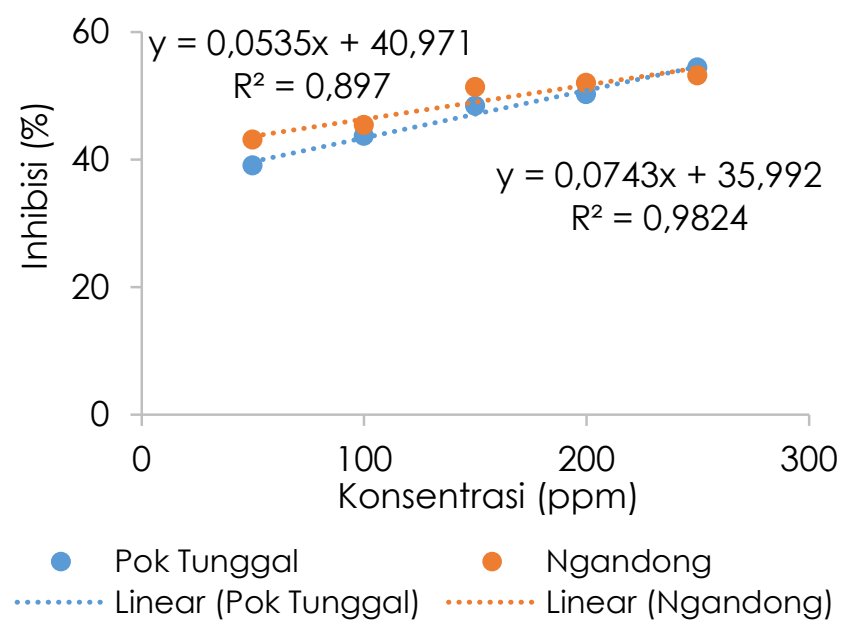

Gambar 2. Grafik konsentrasi ekstrak Gracilaria verrucosa terhadap \% inhibisi.

ekstrak mengacu pada Pramesti et al. (2017). Analisa korelasi regresi untuk memperoleh nilai $I_{50}$. Persamaan regresi linier hubungan antara konsentrasi terhadap persen inhibisi DPPH digunakan untuk menghitung nilai $\mathrm{IC}_{50}$.

Grafik antara konsentrasi ekstrak Gracilaria verrucosa terhadap \% inhibisi (Gambar 2)menunjukkan bahwa kedua ekstrak memiliki nilai inhibisi yang berbanding lurus dengan konsentrasi ekstrak. Hasil pengukuran aktivitas antioksidan pada Gracilaria verrucosa dari kedua pantai didapatkan nilai $\mathrm{IC}_{50}$ sampel yang berbeda. Nilai $I_{50}$ pada ekstrak Gracilaria verrucosa dari pantai Pok Tunggal lebih besar dengan nilai 188,53 ppm dibandingkan pada ekstrak dari Pantai Ngandong dengan nilai 168,76 ppm. Nilai $I_{50}$ pada ekstrak dari kedua pantai lebih kecil dibandingkan dengan penelitian yang dilakukan oleh Lestario et al. (2018) yang memperoleh nilai $\mathrm{IC}_{50}$ yang sangat rendah yaitu 1680,59 ppm untuk ekstrak metanol. Kemampuan antioksidan pada kedua penelitian ini tergolong rendah berdasarkan perhitungan nilai $I_{50}$. Menurut Molyneux (2004) Semakin kecil nilai IC 50 maka aktivitas antioksidan semakin besar.

Rendahnya kemampuan ekstrak dalam mereduksi DPPH diduga dapat terjadi karena sampel yang digunakan masih terdapat pengotor seperti mineral garam. Kepolaran dari pelarut metanol yang digunakan untuk ekstraksi diduga juga mempengaruhi nilai 
IC 50 . Aktivitas antioksidan sangat dipengaruhi oleh metabolisme sekunder seperti senyawa fenolat yang merupakan senyawa semi polar yang akan sempurna terlarut pada pelarut yang semi polar (Yanuarti et al., 2013; Rondonuwu et al., 2017). Menurut Heo et al. (2006), metabolit sekunder pada rumput laut sangat dipengaruhi oleh parameter lingkungan, sehingga sangat dimungkinkan terdapat perbedaan aktivitas antioksidan pada lokasi yang berbeda (Tabel 1).

Hasil uji fitokimia didasarkan kepada reaksi yang terjadi terhadap ekstrak sampel setelah diberikan perekasi pada ekstrak sampel. Pengujian dilakukan berdasarkan metode Suzery dan Kusrini (2004).

Hasil uji kualitatif menunjukkan bahwa kedua sampel memiliki kandungan senyawa bioaktif yang sama. Senyawa alkaloid dan flavonoid merupakan senyawa yang jumlahnya sangat besar dalam tanaman. Hasil pengujian diperkuat dengan penelitian yang telah dilakukan oleh Widowati et al. (2014) dan Cyril et al. (2017) yang mengidentifikasi adanya alkaloid, flavonoid, saponin, fenol, dan terpenoid dalam sampel Gracilaria verrucosa. Lebih lanjut menurut Yuhernita dan Juniarti (2011) senyawa flavonoid, alkaloid, fenol, dan terpenoid merupakan senyawa yang bersifat antioksidan.

Perhitungan kadar total fenolat, klorofila, klorofil-b, dan karotenoid dilakukan

Tabel 1. Keberadaan Metabolit Sekunder dari Rumput Laut Gracilaria verrucosa

\begin{tabular}{lcc}
\hline \multirow{2}{*}{ Uji } & \multicolumn{2}{c}{ Lokasi } \\
\cline { 2 - 3 } & Pok Tunggal & Ngandong \\
\hline Alkaloid & + & ++ \\
Flavonoid & + & + \\
Saponin & + & + \\
Fenol & + & + \\
Steroid & - & - \\
Triterpenoid & ++ & + \\
\hline
\end{tabular}

Ket. + : terjadi perubahan warna/bereaksi; ++ : terjadi perubahan warna lebih pekat/bereaksi lebih kuat; - : tidak terjadi reaksi. menggunakan metode spektrofotometri (Tabel 2). Asam galat digunakan sebagai standar dalam pengukuran kadar total fenolat. Hasil pengujian klorofil-a, dan klorofil$b$, menunjukkan ekstrak sampel dari pantai Pok Tunggal memiliki nilai berturut - turut sebesar $7,132 \mathrm{mg} / \mathrm{g}$, dan $8,833 \mathrm{mg} / \mathrm{g}$. Nilai karotenoid dan total fenolat tertinggi diperoleh dari ekstrak sampel dari pantai Ngandong dengan nilai $35,494 \mu \mathrm{mol} / \mathrm{g}$ dan 17,49 mg GAE/mg sampel.

Kandungan fenolat total pada penelitian ini lebih kecil dibandingkan penelitian Lestario et al. (2008) yang memperoleh fenolat total sebesar $20,01 \mathrm{mg}$ GAE/ g sampel untuk ekstrak metanol namun lebih besar dari penelitian yang dilakukan oleh Widowati et al. (2014) dimana ekstrak Gracilaria verrucosa memiliki kandungan fenolat total sebesar 7,86 mg GAE / g sampel ekstrak metanol.

Kadar klorofil pada ekstrak dari Pantai Pok Tunggal lebih besar dibandingkan dengan ekstrak yang berasal dari Pantai Ngandong. Klorofil-a lebih sedikit dibandingkan dengan klorofil-b pada kedua sampel dikarenakan sifat yang berbeda antara klorofil-a dan klorofil-b. Klorofil-b memiliki sifat yang lebih polar dibandingkan dengan klorofil-a yang kurang polar (Gross, 1991). Diduga penggunaan metanol yang merupakan pelarut polar akan melarutkan lebih banyak klorofil-b dibandingkan klorofila. Lebih lanjut, kandungan zat hara pada perairan juga mempengaruhi jumlah klorofil-a yang dimiliki oleh tumbuhan laut (Aryawati et al., 2014).

Kandungan klorofil berbanding terbalik dengan kandungan karotenoid masing masing sampel. Perbedaan jumlah karotenoid berhubungan dengan intensitas cahaya yang diterima rumput laut. Karoten merupakan aksesoris permanen cahaya yang dapat melindungi kerusakan klorofil oleh foto-oksidasi saat fotosintesis, selain itu karotenoid memiliki peran dalam memanen cahaya (Merdekawati et al, 2017).

Menurut Gross (1991) klorofil yang berada pada tanaman dapat berpotensi sebagai senyawa antioksidan. Dalam proses feofitinisasi terdapat logam $\mathrm{Mg}^{+}$yang 
Tabel 2. Hasil Pengujian Klorofil-a, Klorofil-b, Karotenoid, dan Total Fenolat

\begin{tabular}{ccccc}
\hline Lokasi & $\begin{array}{c}\text { Klorofil-a } \\
(\mathrm{mg} / \mathrm{g})\end{array}$ & $\begin{array}{c}\text { Klorofil-b } \\
(\mathrm{mg} / \mathrm{g})\end{array}$ & $\begin{array}{c}\text { Karotenoid } \\
(\mu \mathrm{mol} / \mathrm{g})\end{array}$ & Fenolat $(\mathrm{mg}$ GAE/g) \\
\hline Pok Tunggal & 7,132 & 8,335 & 31,625 & 16,527 \\
Ngandong & 4,357 & 5,401 & 35,494 & 17,498 \\
\hline
\end{tabular}

terlepas sehingga radikal bebas yang memiliki elektron berlebih akan menyumbangkan elektronnya kepada logam $\mathrm{Mg}^{+}$.

\section{KESIMPULAN}

Gracilaria verrucosa yang diperoleh dari Pantai Pok Tunggal dan Pantai Ngandong memiliki aktivitas antioksidan yang lemah dengan nilai $\mathrm{IC}_{50}$ untuk Pantai Pok Tunggal sebesar $188,53 \mathrm{ppm}$ dan Pantai Ngandong sebesar 168,76 ppm. Pada Pantai Pok Tunggal kadar klorofil-a, klorofil-b, karotenoid, dan kadar fenolat adalah sebesar $7,132 \mathrm{mg} / \mathrm{g}, 8,335 \mathrm{mg} / \mathrm{g}, 31,625$ $\mu \mathrm{mol} / \mathrm{g}$, dan 16,527 mg GAE/g; Pada Pantai Ngandong kadar klorofil-a, klorofil-b, karotenoid, dan kadar fenolat adalah sebesar 4,357 mg/g, 5,401 mg/g, 35,494 $\mu \mathrm{mol} / \mathrm{g}$, dan 17,498 mg GAE/g. Gracilaria verrucosa yang diperoleh dari Pantai Pok Tunggal dan Pantai Ngandong memilik senyawa bioaktif antara lain flavonoid, alkaloid, saponin, fenol, dan triterpenoid, tetapi tidak ditemukan steroid.

\section{DAFTAR PUSTAKA}

Ariani, W. Nurgayah, L.O.A. \& Afu. 2017. Komposisi dan Distribusi Makroalga Berdasarkan Tipe Substrat di Perairan Desa Lalowaru Kecamatan Moramo Utara. Sapa Laut. 2(1):25-30.

Arunkumar, K., Palanivelu, A. \& Darsis, A. 2014. Proximate composition, nutraceutical constituents and fatty acid profile on GCMS of seaweeds collected from Balk Bay (Thondi), India. Int. J. Current Sci. 12:57-71.

Aryawati, R., Isnaini, \& Surbakti, H. 2014. Hubungan Konsentrasi Klorofil-a dan Kandungan Hara di Perairan Bangka. Seminar Nasional MIPA Palembang . 1-6.

Choe, E., \& D. B. Min. 2009. Mechanisms of Antioxidants in the Oxidation of Foods.
Comprehen. Rev. Food Sci. Food Safety. 8(4):345 - 359.

Cyril, R., Lakshmanan, R. \& Thhiyagarajan, A. 2017. In Vitro Bioactivity and Phytochemical Analysis of Two Marine Macro-algae. J. Coast. Life Med. 5(10): 427-432.

De Almeida, C.L.F., Falcão, D.S., Lima, D.M., Gedson, R., Montenegro, D.A., Lira, N.S., Athayde-Filho, D., Petrônio, F., Rodrigues, L.C., De Souza, M.D.F.V. and BarbosaFilho, J.M., 2011. Bioactivities from marine algae of the genus Gracilaria. Int. J. Mol. Sci., 12(7):4550-4573.

Fitri, N. 2013. Butylated hydroxyanisole sebagai Bahan Aditif Antioksidan pada Makanan dilihat dari Perspektif Kesehatan. J. Kefarmasian Ind. 4(1):41-50.

Gross, J. 1991. Pigments in Vegetables Chlorophylls and Carotenoids. An Avi Book. New York

Hanapi, A., Fasya, G., Mardiyah, U., \& Miftahurrahmah. 2013. Uji Aktivitas Antioksidan Dan Antibakteri Ekstrak Metanol Alga Merah Eucheuma spinosum Dari Perairan Wongsorejo Banyuwangi. J. Alchemy, 2(2):126-137.

Kurniawan, M., Munifatul, I. \& Yulita, N. 2010. Kandungan Klorofil, Karotenoid, dan Vitamin C pada Beberapa Spesies Tumbuhan Akuatik. Anatomi Fisiologi. 18(1):28-40.

Lestario, L. N., Sugiarto, S., \& Timotius, K.H. 2008. Aktivitas Antioksidan dan Kadar Fenolik Total dari Ganggang Merah (Gracilaria verrucosa L.). J. Teknol. Ind. Pangan, 19(2):131-139.

Lichtenthaler, H.K. 1987. Chlorophylls And Carotenoids: Pigments Of Photosynthetic Biomembranes. Methods in Enzymology. 148:350-382.

Merdekawati, W., Karwur, F.K. \& Susanto, A.B. 2017. Karotenoid Pada Algae: Kajian Tentang Biosintesis, Distribusi Serta Fungsi Karotenoid. Bioma 13(1):23-33.

Molyneux, P. 2004. The Use of The Stable Free Radical diphenylpicryl-hydrazyl for 
Estimating Antioxidant Activity. Songklanakarin J. Sci. Technol. 26(2):211219.

Pramesti, R., Ridlo, A., Setyati, W.A., Zainuddin, M., \& Akbar, M.R. 2017. Aktivitas Antioksidan Rumput Laut Acanthophora muscoides (Linnaeus) Bory dari Pantai Krakal Gunung Kidul Yogyakarta. J. Disprotek, 8(1):46-56.

Pumas, C., Peerapornpisal, Y., Vacharapiyasophon, P., Leelapornpisid, P., Boonchum, W., Ishii, M. \& Khanongnuch, C. 2012. Purification and characterization of a thermostable phycoerythrin from hot spring cyanobacterium leptolyngbya sp. KC45. Int.l J. Agricul. \& Biolog. 14:121-125.

Rohimat. R, Widowati, I., \& Trianto, A. 2014. Aktifitas antioksidan ekstrak metanol rumput laut coklat (Turbinaria conoides dan Sargassum cristaefolium) yang dikoleksi dari pantai Rancabuaya Garut Jawa Barat. J. Mar. Res.3(3):304-313.

Rondonuwu, S.D.J., Suryanto, E., \& Sudewi, S. 2017. Kandungan Total Fenolik dan Aktivitas Antioksidan dari Pelarut Sagu Baruk (Arenga microcharpa). Chem. Prog., 10(1):31-35

Sani, R.N., Nisa, F.C., Andriani, R.D. \& Maligan, J.M.. 2014. Analisis Rendemen dan Skrining Fitokimia Ekstrak Etanol Mikroalga Laut Tetraselmis chuii. J.Pangan Agroind. 2(2):121-126.

Santoso, J., Anwariyah, S., Rumiantin, R.O., Putri, A.P., Ukhty, N. \& Yoshie-Stark, Y., 2012. Phenol content, antioxidant activity and fibers profile of four tropical seagrasses from Indonesia. J. Coast. Dev. 15(2):189-196.

Saxena, M., Saxena, J., Nema, R., Singh, D. \& Gupta, A., 2013. Phytochemistry of medicinal plants. J. Pharmacog. Phytochem. 1(6):168-182.
Sayuti, K. \& Yenrina, R. 2015. Antioksidan, Alami dan Sintetik. Andalas Universitiy Press, Padang

Sayuti, M. 2017. Pengaruh Perbedaan Metode Ekstraksi, Bagian Dan Jenis Pelarut Terhadap Rendemen Dan Aktifitas Antioksidan Bambu Laut (Isis Hippuris). Technol. Sci. Eng. J. 1 (3):166-174

Sharma, G.N., Dubey, S.K., Sati, N. \& Sanadya, J., 2011. Phytochemical screening and estimation of total phenolic content in Aegle marmelos seeds. Int. J. Pharmaceut. Clinic. Res. 3(2):27-29.

Shekhar, T.C. \& Anju, G., 2014. Antioxidant activity by DPPH radical scavenging method of Ageratum conyzoides Linn. leaves. Am. J. Ethnomed. 1 (4):244-249.

Suzery, M. \& Kusrini, D., 2004. Buku Ajar Pemisahan dan Analisis Bahan Alam. FMIPA, UNDIP, Semarang. 131.

Widowati, I., Lubac, D., Puspita, M. \& Bourgougnon, N. 2014. Antibacterial and Antioxidant Properties of The Red Alga Gracilaria verrucosa from The North Coast of Java, Semarang, Indonesia. Int. J. Latest Res. Sci. Technol. 3(3):179-185

Yadav, A., Kumari, R., Yadav, A., Mishra, J.P., Srivatva, S. \& Prabha, S., 2016. Antioxidants and its functions in human body-A Review. Res. Environ. Life Sci. 9(11):1328-1331.

Yangthong, M., Hutadilok-Towatana, N. \& Phromkunthong, W. 2009. Antioxidant Activities of Four Edible Seaweeds from the Southern Coast of Thailand. Plant Foods Human Nutrition, 64:218-223

Yuhernita \& Juniarti. 2011. Analisis Senyawa Metabolit Sekunder dari Ekstrak Metanol Daun Surian yang Berpotensi Sebagai Antioksidan. Makara, Sains, 15(1):48-52. 